\title{
Pattern and process in the evolution of the sole dioecious member of Brassicaceae
}

\author{
Valerie L Soza, Vietnam Le Huynh and Verónica S Di Stilio*
}

\begin{abstract}
Background: Lepidium sisymbrioides, a polyploid New Zealand endemic, is the sole dioecious species in Brassicaceae and therefore the closest dioecious relative of the model plant Arabidopsis thaliana. The attractiveness of developing this system for future studies on the genetics of sex determination prompted us to investigate historical and developmental factors surrounding the evolution of its unisexual flowers. Our goal was to determine the evolutionary pattern of polyploidization of L. sisymbrioides and the timing and process of flower reproductive organ abortion. To that end, we used a combination of phylogenetics to place this species within the complex history of polyploidization events in Lepidium and histology to compare its floral ontogeny to that of its closest hermaphroditic relatives and to $A$. thaliana.

Results: Using a nuclear locus (PISTILLATA), we reconstructed the gene tree among Lepidium taxa and applied a phylogenetic network analysis to identify ancestral genomes that contributed to the evolution of L. sisymbrioides. Combining this phylogenetic framework with cytological and genome size data, we estimated L. sisymbrioides as an allo-octoploid resulting from three hybridization events. Our investigations of flower development showed that unisexual flowers appear to abort reproductive organs by programmed cell death in female flowers and by developmental arrest in male flowers. This selective abortion occurs at the same floral developmental stage in both males and females, corresponding to Arabidopsis stage nine.

Conclusions: Dioecy in Brassicaceae evolved once in L. sisymbrioides following several allopolyploidization events, by a process of selective abortion of reproductive organs at intermediate stages of flower development. Different developmental processes, but similar timing of abortions, affect male versus female flower development. An increased understanding of how and when reproductive organs abort in this species, combined with our estimates of ancestral genome contributions, ploidy and genome size, lay the foundation for future efforts to examine the genetic mechanisms involved in the evolution of unisexual flowers in the closest dioecious relative of the best studied model plant.
\end{abstract}

Keywords: allopolyploidy, programmed cell death, dioecy, floral ontogeny, genome size, organ arrest, phylogenetic network, PISTILLATA, sex differentiation, unisexual flowers

\section{Background}

The family Brassicaceae contains approximately 338 genera and 3,709 species [1,2] and includes the model plant Arabidopsis thaliana, which has a floral morphology representative of the vast majority of the family. Only $5 \%$ of genera within Brassicaceae show deviations from the basic floral plan of four sepals, four petals, six stamens (four medial and two lateral), and two fused carpels [3]. One of these genera that diverge from the basic Brassicaceae

\footnotetext{
*Correspondence: distilio@uw.edu

Department of Biology, University of Washington, Box 351800, Seattle, WA 98195-1800, USA
}

(c) 2014 Soza et al.; licensee BioMed Central Ltd. This is an Open Access article distributed under the terms of the Creative Commons Attribution License (http://creativecommons.org/licenses/by/4.0), which permits unrestricted use, distribution, and reproduction in any medium, provided the original work is properly credited. The Creative Commons Public Domain Dedication waiver (http://creativecommons.org/publicdomain/zero/1.0/) applies to the data made available in this article unless otherwise stated. floral morphology, Lepidium (230 species [1]), is widely distributed in temperate and subtropical areas [4]. Earlydiverging lineages in the genus comprise outcrossing diploid species from the Old World that exhibit the basic floral plan of the family, whereas derived lineages tend to be selfing allopolyploids from the New World, Australia, and New Zealand with reduced flowers (that is, fewer stamens and/or reduced petals) [5]. Among the latter, the New Zealand endemic Lepidium sisymbrioides is the only dioecious species in the whole Brassicaceae [4,6-10]. Staminate flowers of $L$. sisymbrioides consist of four to six stamens and a reduced ovary $[10,11]$, whereas carpellate 
flowers have three to seven staminodes and a functional pistil with style and stigma [10]. Nonfunctional reproductive organs of unisexual flowers of $L$. sisymbrioides have been loosely described as 'abortive' $[8,11]$, but the exact timing and process of the abortions remain unknown.

Incongruence between phylogenetic trees using nuclear versus chloroplast DNA regions suggests reticulate evolution within the genus [12]. It appears that hybridization, followed by whole genome duplication, resulted in predominantly allopolyploid Lepidium species in the Americas, Australia, and New Zealand [5]. These hybridization events may have contributed to the reduced stamens and petals observed in these species [5], in which case dioecy could represent another example of organ reduction.

In angiosperms, dioecy often follows polyploidization, presumably due to chromosomal rearrangements that facilitate the evolution of sex chromosomes or the breakdown of gametophytic self-incompatibility, followed by inbreeding depression [13-15]. Correlations between island habitat and dioecy are also common, through selection for outcrossing in small, colonizing hermaphroditic populations, [16]. In fact, New Zealand taxa in general show a higher incidence of gender dimorphism compared to their continental sister taxa $[17,18]$. Combined evidence for reticulate evolution and polyploidy in New Zealand Lepidium [5,12] suggests that L. sisymbrioides may also be an allopolyploid. We therefore hypothesize that this species represents another case of dioecy evolving in an island species, following hybridization and polyploidization.

The lineages containing Lepidium and Arabidopsis diverged from each other relatively recently, approximately 35 million years ago (mya) [19]. Lepidium sisymbrioides, therefore, offers the potential to uncover the genetic mechanisms involved in the evolution of unisexual flowers by being the closest dioecious relative to the most thoroughly investigated model plant. Determining the developmental stage and process of reproductive organ abortion should facilitate the identification of candidate genes involved in the evolution of unisexual flowers in this species as genes involved in sporogenesis and gametogenesis have been identified in Arabidopsis [20,21]. Six developmental processes leading to reproductive organ abortion in unisexual flowers are recognized: cell death, programmed cell death, parenchymatization, arrest of development, change in timing of otherwise normal developmental events, and inviable pollen [22]. Identifying which of these processes contributes to the development of male and female flowers in L. sisymbrioides, as well as estimating this species' genome size and ploidy history, will facilitate future efforts to uncover the genetic mechanisms involved in the evolution of dioecy.

The overall goal of this study was to investigate the pattern of polyploidization and the developmental processes underlying the evolution of separate sexes in L. sisymbrioides, the sole dioecious member of Brassicaceae. To that end, we 1) identified ancestral genomes within $L$. sisymbrioides and close relatives, 2) estimated ploidy and genome size for L. sisymbrioides and close relatives and 3) investigated the timing and process of organ abortion by comparing its floral development to that of its close hermaphroditic relatives and to Arabidopsis thaliana.

\section{Methods \\ Sampling methods}

Three subspecies of L. sisymbrioides were originally recognized: kawarau (Petrie) Thell., matau (Petrie) Thell., and sisymbrioides. All have been listed as nationally endangered because of a steep reduction in their distribution and abundance [23] and are difficult to sample. We sampled $L$. sisymbrioides subsp. sisymbrioides only because, despite reported habitat and morphological differences, all three subspecies are closely related [10].

In addition to published DNA sequences of Lepidium available from GenBank (Appendix 1), we sampled $L$. sisymbrioides subsp. sisymbrioides and three hermaphroditic close relatives endemic to New Zealand, L. kirkii, $L$. naufragorum and L. tenuicaule $[9,10,12,24,25]$. We sampled L. kirkii from an herbarium specimen (Appendix 1) and the remaining three species from cultivated accessions at the University of Washington (UW) greenhouse from wild-collected seed provided by P. Heenan (Landcare Research, Lincoln, New Zealand). Voucher specimens are listed in Appendix 1.

\section{Molecular methods}

Because we were primarily interested in the polyploidization history of $L$. sisymbrioides and its close relatives (L. kirkii, L. naufragorum, and L. tenuicaule), we investigated reticulation events using the single-copy nuclear gene PISTILLATA (PI). PI had been previously used to detect reticulation among other Lepidium taxa [5] and therefore sequences were readily available (Appendix 1). Genomic DNA was extracted from one to two accessions for each of our four study species using the FastDNA Kit (MP Biomedicals, Solon, OH, USA) for cultivated accessions or following the protocol of Hughey et al. [26] for the herbarium specimen. We amplified and sequenced the first intron of PI using PI-ITF and PI-ITR primers [5]. Polymerase chain reaction conditions were $95^{\circ} \mathrm{C}$ for $2 \mathrm{~min}$, followed by 35 cycles of $94^{\circ} \mathrm{C}$ for $30 \mathrm{~s}, 60^{\circ} \mathrm{C}$ for $1 \mathrm{~min}$, and $72^{\circ} \mathrm{C}$ for $1 \mathrm{~min}$, with a final extension step at $72^{\circ} \mathrm{C}$ for 5 min. Amplified DNA was purified using ExoSAP-IT (USB Corporation, Cleveland, OH, USA).

To distinguish among allelic variants, PCR products were cloned into the pCRII or pCR2.1 vector using the TA Cloning Kit (Invitrogen Corporation, Carlsbad, CA, USA). Plasmids were extracted using the FastPlasmid 
Mini Kit (5 Prime Inc., Gaithersburg, MD, USA). Three to 27 positive clones were sequenced per accession (UW Biochemistry DNA Sequencing Facility or GENEWIZ, Seattle, WA, USA) for a total of 20 to 35 clones per taxon.

\section{Phylogenetic analyses}

PISTILLATA sequences were edited in Sequencher 4.9 (Gene Codes Corporation, Ann Arbor, MI, USA). We incorporated sequences we generated from our four study species plus available sequences from other taxa in GenBank to the entire alignment of the PI first intron, provided by J. L. Bowman [5]. We then aligned all sequences manually using MacClade 4.08 [27]. Ambiguously aligned regions were excluded from subsequent analyses. Our data set is available through TreeBASE (http://purl.org/phylo/ treebase/phylows/study/TB2:S11886).

In order to detect whether PCR-mediated recombination had occurred among the PI copies within a species, we checked for recombination using RDP4 [28]. The PI alignment was analyzed by the automated exploratory recombination analysis, which employs eight different recombination methods: RDP [29], BootScan [30], GENECONV [31], MaxChi [32], Chimaera [33], SiScan [34], 3Seq [35], and LARD [36]. Analyses were run under the default general settings but as linear sequences and disentangling overlapping signals. The default settings for each method were used except for the following models: Felsenstein 1984 for BootScan and reversible process for LARD. Five recombinant sequences were identified and removed from the $P I$ alignment before subsequent phylogenetic analyses.

We reconstructed the phylogeny for the Lepidium PI data set using Bayesian and likelihood analyses. For taxa that had multiple clonal PI sequences, we chose one clonal sequence from each monophyletic group of sequences representing a given taxon that was recovered in a $50 \%$ majority rule consensus tree from preliminary Bayesian analyses of all clones and that was representative of the majority of clones from a group. All other clonal sequences not forming monophyletic groups with other clones from the same taxon were included in the final analyses (Appendix 1).

For Bayesian and likelihood analyses, the model of evolution for the PI data set was determined by jModelTest $2.1[37,38]$. The model selected under the Akaike Information Criterion [39] was TVM $+\mathrm{I}+\Gamma$. We specified $L$. phlebopetalum and L. perfoliatum as outgroups, as previously identified in various studies $[5,9,25,40]$.

Bayesian analyses were conducted in MrBayes 3.2.2 $[41,42]$ via the CIPRES Science Gateway 3.3 [43]. We used default priors of no prior knowledge for the parameters of the model. Bayesian analyses were conducted with three independent Markov Chain Monte Carlo [44] analyses of 10 million generations each. Metropolis coupling for each analysis was conducted under the default settings. Convergence was determined when the average standard deviation of split frequencies remained less than 0.01. The first $10 \%$ of trees was discarded before convergence. The remaining trees from each run were pooled to construct a $50 \%$ majority rule consensus tree to obtain posterior probabilities (pp) and visualized with FigTree 1.4 [45].

Likelihood analyses were conducted in GARLI 2.0 [46]. Analyses were run under the default settings and included five search replicates to determine the maximum likelihood tree. To assess the reliability of clades in the resulting likelihood tree, we conducted 1,000 nonparametric bootstrap (bs) replicates [47] in GARLI. Bootstrap replicates were conducted under the above settings, but included one search replicate and 10,000 generations as the first part of the termination condition. Bootstrap trees were summarized with SumTrees 3.3.1 [48] and visualized with FigTree.

Since multiple PI copies in polyploid Lepidium taxa had been previously ascribed to allopolypoidy [5], we wanted to identify potential hybridization events leading to the evolution of dioecy in L. sisymbrioides. To facilitate visualization of potential ancestral genomes that contributed to the evolution of $L$. sisymbrioides and its close relatives ( $L$. kirkii, $L$. naufragorum, $L$. tenuicaule), we conducted network analyses using the $50 \%$ majority rule consensus tree from Bayesian analyses of the PI data set as a multilabeled tree (MUL tree). The MUL tree was imported into Dendroscope 3.2.10 [49] and transformed into a phylogenetic network using the Huber et al. [50] algorithm, which minimizes the number of hybridization nodes.

\section{Cytology}

Chromosome counts were obtained from pollen mother cells (PMCs) from freshly collected floral buds from one to two cultivated accessions of $L$. sisymbrioides and $L$. tenuicaule using a modified protocol of Kato [51]. Floral buds were treated according to the protocol of Matsushita et al. [52] and Wright et al. [53], modified with an $\mathrm{N}_{2} \mathrm{O}$ treatment for 3 hours at 206 PSI and an enzyme digestion for 3 hours. PMCs were mounted in VECTASHIELD with DAPI (Vector Laboratories, Burlingame, CA, USA), observed and photographed using a Nikon Microphot-FX microscope (Nikon Instruments, Inc., Melville, NY, USA) and a Retiga 1300 monochrome camera (QImaging, Surrey, British Columbia, Canada).

\section{Genome size estimation}

Three accessions from three species cultivated at the UW greenhouse ( $L$. naufragorum, $L$. sisymbrioides, and L. tenuicaule) were analyzed to obtain relative holoploid genome size, expressed as a $1 \mathrm{C}$-value as defined in [54]. Nuclei were extracted from fresh leaf tissue and combined with chicken erythrocyte nuclei (CEN singlets, BioSure, Grass 
Valley, CA, USA) before staining with propidium iodide and analyzed with a flow cytometer, as outlined in Davison et al. [55]. CEN, with a $1 \mathrm{C}$-value of $1223 \mathrm{Mbp}$ or $1.25 \mathrm{pg}$ [56], were used as an internal calibration standard. Animal standards have been discouraged by some authors for plant studies because (1) they cannot account for the huge range of plant genome sizes, (2) their nuclei structure may be different from plant nuclei, and (3) their precise genome size is unknown [57]. However, for our purposes, the genome size of CEN falls within the range of Lepidium genome size estimates. Additionally, our goal was to produce relative holoploid genome size estimates, since absolute estimates are not feasible due to the lack of complete genome coverage in most model taxa because of repetitive regions in the genome [55,57].

Samples were analyzed on a FACScan flow cytometer (Becton, Dickinson and Company, Franklin Lakes, NJ, USA) with FlowJo software (Tree Star, Ashland, OR, USA) at the UW Department of Immunology Cell Analysis Facility. The $2 \mathrm{C}$ median nuclear peak of propidium iodide fluorescence in Lepidium samples was compared to that of the CEN standard to estimate the $2 \mathrm{C}$ nuclear DNA content of Lepidium in Mbp, then converted to pg using the equation from Dolezel et al. [58].

\section{Floral development observations}

Floral tissue of L. naufragorum, L. sisymbrioides, and L. tenuicaule was dissected and fixed overnight in formaldehyde-acetic acid-alcohol (FAA). Prior to scanning electron microscopy (SEM), tissue was dehydrated through an ethanol series (30 min each of 50\%, 60\%, $70 \%, 85 \%, 95 \%$ and $100 \%$ ), critical-point dried, mounted, and sputter coated at the UW Department of Biology Imaging Facility. Observations were made with a JSM840A scanning electron microscope (JEOL, Peabody, MA, USA).

The relative timing of floral organ initiation and growth in Lepidium taxa had been previously shown to be comparable to that of its model Brassicaceae relatives (that is, Arabidopsis thaliana and Brassica napus), with the exception of petal growth and stamen number $[59,60]$. Therefore, floral developmental stages for our three Lepidium study species were designated by the 13 characterized stages of the closely related model Arabidopsis thaliana $[20,61,62]$.

For histological observations, inflorescences were fixed in FAA, then dehydrated through an ethanol series ending in Citrisolv (Fisher Scientific, Kent, WA, USA), embedded in Paraplast Plus (McCormick Scientific, LLC, St. Louis, MO, USA), and sectioned (5 or $8 \mu \mathrm{m}$ ) according to the protocol of Kramer [63]. Slides were deparaffinized with CitriSolv, hydrated through an ethanol series, stained in 1\% Safranin O for 24 hr [64] and counterstained with $0.5 \%$ Fast Green FCF for $30 \mathrm{sec}$ or stained in $0.05 \%$ Toluidine Blue $\mathrm{O}$ in $\mathrm{dH} 2 \mathrm{O}$ for 1 to $2 \mathrm{~min}$, and dehydrated through an ethanol series ending in CitriSolv. Histological sections were mounted in Cytoseal $^{\mathrm{TM}}$ 60 (Richard-Allan Scientific, Kalamazoo, MI, USA) and observed using a Leica TCS SP5 II laser scanning confocal microscope (Leica Microsystems Inc., Buffalo Grove, IL, USA) with an excitation of $488 \mathrm{~nm}$ and an emission of 500 to $560 \mathrm{~nm}$ for Safranin $\mathrm{O}$ and an excitation of $561 \mathrm{~nm}$ and an emission of 625 to $690 \mathrm{~nm}$ for Fast Green FCF or using a Leitz Orthoplan 2 microscope (Ernst Leitz, Midland, Ontario, Canada) and photographed with a MicroPublisher 3.3 Real-Time Viewing camera (QImaging, Surrey, British Columbia, Canada).

\section{TUNEL assays}

We conducted TUNEL assays to determine whether programmed cell death (PCD) was occurring in aborted stamens from L. sisymbrioides female flowers. Paraffinembedded tissue sections were prepared as outlined above from female L. sisymbrioides and male L. sisymbrioides and hermaphroditic L. tenuicaule for comparison. We used the DeadEnd Fluorometric TUNEL System (Promega Corporation, Madison, WI, USA) according to manufacturer's instructions, including positive controls, and washed slides in PBS containing $0.1 \%$ Triton $^{\odot} \mathrm{X}-100$ and $5 \mathrm{mg} / \mathrm{ml}$ of BSA after terminating reactions to reduce background as recommended. Slides were mounted in VECTASHIELD with DAPI, except for negative control slides that were untreated and mounted in Cytoseal ${ }^{\mathrm{TM}} 60$. Slides were observed using a Leica TCS SP5 II laser scanning confocal microscope using an excitation of $405 \mathrm{~nm}$ and an emission of 430 to $550 \mathrm{~nm}$ for DAPI and an excitation of $488 \mathrm{~nm}$ and an emission of 500 to $535 \mathrm{~nm}$ for fluorescein.

\section{Results}

PISTILLATA gene duplication history suggests allopolyploidy in Lepidium sisymbrioides and relatives

In order to identify hybridization events leading to the evolution of the dioecious species L. sisymbrioides and its closest hermaphroditic relatives, L. kirkii, L. naufragorum and $L$. tenuicaule, we amplified and sequenced the first intron of the single-copy nuclear gene PI from these species and aligned them to other Lepidium sequences available in GenBank or unpublished (provided by J. L. Bowman; Appendix 1). Phylogenetic analyses recovered five, strongly supported clades (A1-D; pp $\geq 0.99$, bs $\geq 94 \%$; Figure 1) representing five major copies of the $P I$ intron from American, Australian, and New Zealand (AANZ) taxa. Multiple copies of the PI intron within a taxon were previously suggested as representing multiple genomes from allopolyploid hybridization [5]. Clades A1 and A2 were denoted here because they had been previously recognized as a single clade 'A', but with low support [5]. In our analysis, these two clades are strongly supported 


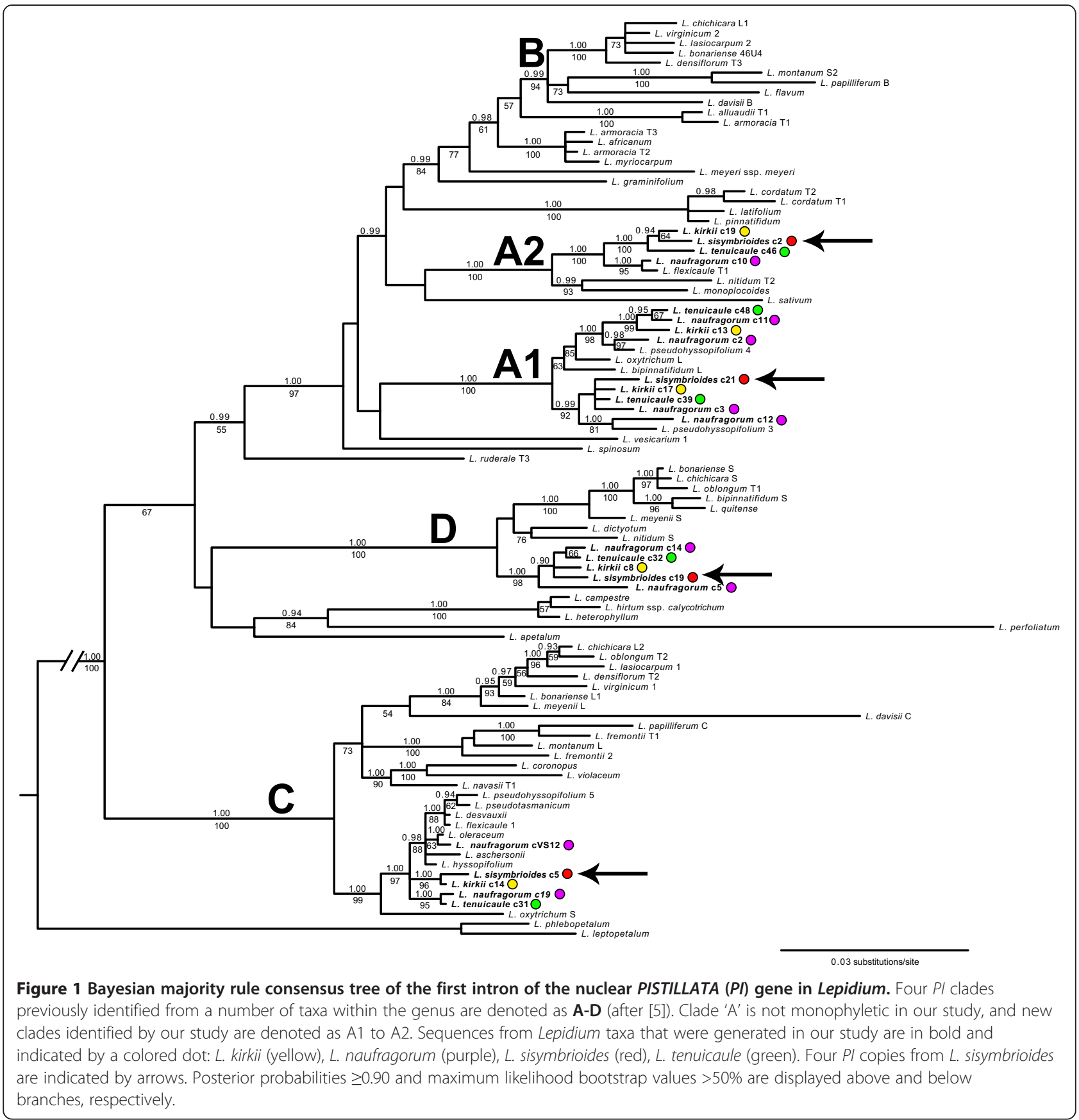

as distinct ( $\mathrm{pp}=1.00, \mathrm{bs}=100 \%)$ and indicative of two separate genomes, as evidenced by sequences from our four study species in both clades (Figure 1, colored dots). Therefore, we found at least four distinct copies of the PI intron in L. kirkii [GenBank:KJ648155-KJ648159], L. naufragorum [GenBank: JN119859-JN119860/JN11986 2/KJ648160-KJ648165], L. sisymbrioides [GenBank: KJ6 48166-KJ648169], and L. tenuicaule [GenBank:KJ6481 70-KJ648174], representing clades A1, A2, C, and D (Figure 1). In addition, multiple sequences of $L$. kirkii, $L$. naufragorum, L. pseudohyssopifolium, and/or L. tenuicaule within clades A1, C, and D (Figure 1) suggest that hybridization, gene duplication and/or allelic divergence are at play. None of the New Zealand taxa studied fell into the fifth clade B, which consists entirely of American taxa. Our results therefore suggest that all four New Zealand species are allopolyploids (and potentially allo-octoploids at minimum), originating from at least four divergent genomes (represented by clades A1, A2, C, and D).

We further used the Bayesian majority rule consensus tree from the PI data set (Figure 1) to estimate a phylogenetic network to aid in the identification of hybridization 
nodes and potential ancestral genomes contributing to our study species (Figure 2). According to the network, our sampling includes 21 allopolyploid Lepidium taxa (Figure 2, tree branches originating from curved lines), which are confirmed polyploids from the literature [5] and this study (L. sisymbrioides, L. tenuicaule). The remaining 31 taxa in our analyses do not show evidence of reticulation, and this may be due to diploidy, autopolyploidy, or gene loss.

The evidence suggests that Lepidium sisymbrioides is derived from four distinct ancestral genomes (Figure 2, red lines): (1) a hybrid between (a) a descendant from the common ancestor of the L. monoplocoides group and (b) the common ancestor of the group that includes $L$. pseudotasmanicum and L. hyssopifolium (strong support),
(2) a descendant from the common ancestor of the L. vesicarium group (low support), and (3) a descendant from the common ancestor of the L. dictyotum and L. quitense group (strong support). Biogeographically, the contribution of these genomes to $L$. sisymbrioides implies hybridization among Australian and New Zealand (ANZ) taxa (1a and 1b, above), followed by hybridization with American (3) and potentially (with low support) Asian (2) species. The other three New Zealand study species, $L$. kirkii, L. naufragorum, and L. tenuicaule, show contributions from four, five, and four distinct ancestral genomes, respectively (Figure 2). Of these three close hermaphroditic relatives, $L$. sisymbrioides shares the most reticulation history with $L$. kirkii, followed by $L$. tenuicaule, then $L$. naufragorum (Figure 2).

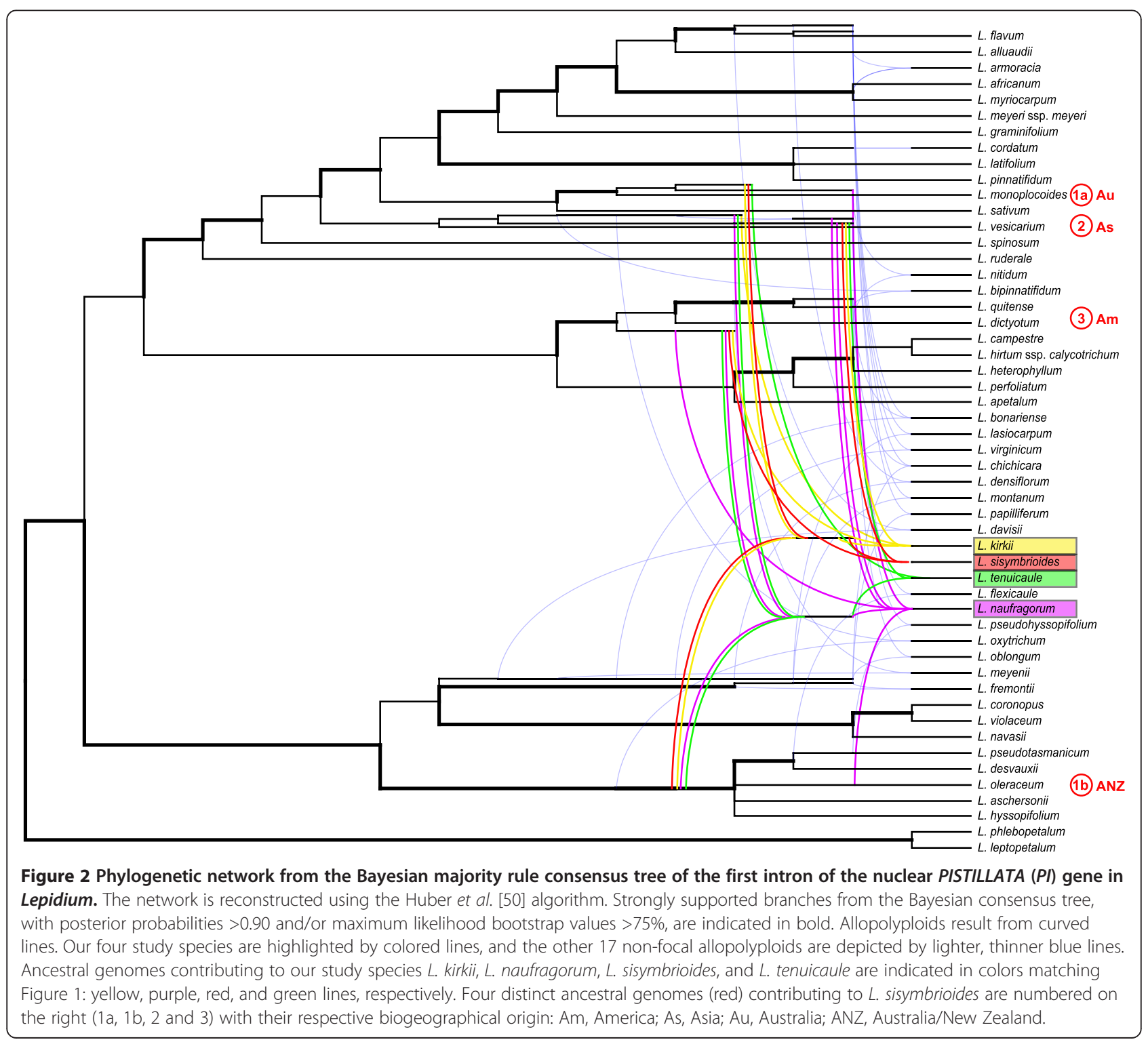


Cytological observations reveal octoploidy in dioecious L. sisymbrioides and its hermaphroditic relative L. tenuicaule

In order to confirm our results from the PI data set, we conducted chromosome counts in PMCs. Seed of L. kirkii was not available, so its chromosome number remains unknown.

Both L. sisymbrioides and L. tenuicaule had $2 n=64$ chromosomes (Figure 3), corresponding to a ploidy of $8 x(x=8$ is the base chromosome number for the genus $[2,4])$. Octoploidy in these two species is consistent with having four distinct copies of the $P I$ intron as shown by our phylogenetic and network analyses (A1, A2, C, D, Figures 1, 2). These four copies would therefore represent four distinct diploid genomes in these species' history of hybridization and polyploidization events.

\section{Genome size estimations confirm ploidy estimates in Lepidium sisymbrioides and relatives}

We examined holoploid genome size by calculating $1 \mathrm{C}$-values for three of our New Zealand Lepidium study species to confirm our estimates of ploidy and to inform future genomic sequencing plans. Lepidium sisymbrioides and L. tenuicaule had similar holoploid genome sizes of 0.63 and $0.66 \mathrm{pg}$, respectively, whereas L. naufragorum's holoploid genome size was slightly over double that of the other two species at $1.41 \mathrm{pg}$ (Table 1). Material from which the holoploid genome size of $L$. naufragorum was obtained had published chromosome counts from the same population, indicating a ploidy of approximately $18 x$ [65]. In conclusion, our holoploid genome size estimations are consistent with $L$. sisymbrioides and L. tenuicaule both being $8 x$ and with $L$. naufragorum being $18 x$, more than double the ploidy of the former two species.
Female and male flowers of Lepidium sisymbrioides abort reproductive organs at comparable developmental stages but due to different processes

In order to assess the developmental stage and process of abortion of reproductive organs in L. sisymbrioides, we examined floral morphology and ontogeny of this species in comparison to the two closest hermaphroditic relatives available, L. naufragorum and L. tenuicaule. Since floral developmental stages of hermaphroditic Lepidium species are comparable to the A. thaliana ontogenetic staging $[20,61,62]$, we cross-referenced to this system for convenience and reproducibility. Flower morphology of $L$. naufragorum and $L$. tenuicaule differed from $A$. thaliana in petal size, number and arrangement of stamens, and ovule number. Lepidium naufragorum flowers had petals approximately as long as sepals and two lateral and two medial stamens (Figure 4A), whereas L. tenuicaule flowers had highly reduced petals, unnoticeable to the naked eye, and four medial stamens (Figure 4B). All Lepidium taxa produced a single ovule per locule.

In contrast to L. naufragorum and L. tenuicaule, both male and female flowers of $L$. sisymbrioides generally exhibited six stamens (two lateral and four medial; Figure 4C-F) with a few exceptions where only four medial (Figure 5O) or five stamens were found [see Additional file 1]. Petals were reduced (that is, shorter than sepals; Figure 4C-F, arrowheads), and four to six nectaries were present among the stamen filaments in both sexes (Figure 4D, F, asterisks; [see Additional file 1]). In staminate flowers, the gynoecium arrested its development at intermediate stages, after differentiation of the anther locules (Figure 4C) and remained as a pistillode while stamens expanded normally (Figure 4D), as in $L$. naufragorum and L. tenuicaule (Figure 4A-B). In young carpellate flowers, stamens and carpels looked normal (Figure 4E). In later stages, however, stamen development was visibly arrested resulting in staminodia, whereas the
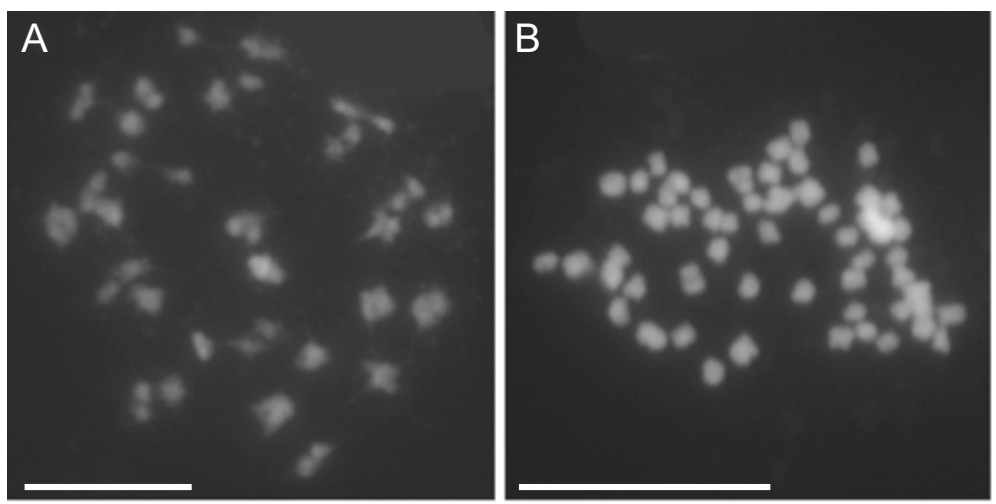

Figure 3 Chromosome spreads from pollen mother cells of Lepidium sisymbrioides and L. tenuicaule. (A) L. sisymbrioides: 32 pairs observed during late Prophase I of meiosis. (B) L. tenuicaule: approximately 64 chromosomes observed during early Prophase I of meiosis. Scale bar $=100 \mu \mathrm{m}$. 
Table 1 Mean holoploid genome size (1C-value) and ploidy estimates for three Lepidium species investigated

\begin{tabular}{lccc}
\hline Species & $\begin{array}{c}\text { 1C-value } \\
\text { (Mbp +/- s.d.) }\end{array}$ & 1C-value (pg) & $\begin{array}{c}\text { Estimated } \\
\text { ploidy level }^{\mathbf{a}}\end{array}$ \\
\hline L. sisymbrioides & $621+/-7.84$ & 0.635 & $\mathbf{8 \mathbf { x } ^ { \mathbf { b } }}$ \\
L. tenuicaule & $645+/-29.41$ & 0.660 & $\mathbf{8 \mathbf { x } ^ { \mathbf { b } }}$ \\
L. naufragorum & $1379+/-61.56$ & 1.410 & $18 \mathrm{x}^{\mathrm{c}}$ \\
\hline
\end{tabular}

aploidy estimates resulting from this study in bold.

${ }^{\mathrm{b}}$ This study, estimated based on chromosome counts (Figure 3). '[65].

gynoecium developed normally (Figure 4F) as in L. naufragorum and L. tenuicaule (Figure 4A-B). From these morphological observations, both carpels and stamens from male and female flowers of $L$. sisymbrioides, respectively, appeared to abort at intermediate stages of flower development.

SEM of flower development in all three species showed flower meristems that initiated from the inflorescence meristem in a similar fashion to Arabidopsis (Figure 5A-B, D, Arabidopsis stages 1 to 2). As expected, sepal primordia developed first (Figure 5A-D, stages 3 to 4), followed by petals (Figure $5 \mathrm{~B}$ ), then presumably stamen and gynoecium primordia. Stamen filaments and anther locules differentiated within the androecium and the gynoecium developed as a tube through postgenital fusion of two carpels (Figure 5E-F, stages 7 to 8). Subsequently, L. naufragorum started to show more petal expansion than the other two species (compare Figure 5E-H). The gynoecial tube then closed at completion of postgenital fusion and began to differentiate a stigma with papillae (Figure 5I-J, L, stage 11). In staminate flowers of L. sisymbrioides, after filaments and anther locules of the androecium had differentiated from one another, the gynoecium was arrested in its development (Figure 5K). The carpels of functional gynoecia expanded laterally, elongating and reaching full maturity with a clearly differentiated style and stigma (Figure 5M-N, P, stage 12). In L. sisymbrioides staminate flowers, the gynoecium remained aborted at maturity (Figure 50) in comparison to functional gynoecia described above. Stamen filaments continued to elongate (Figure 5M-O, stage 12), except in carpellate flowers of $L$. sisymbrioides where they remained much shorter than the gynoecium (Figure 5P). In $L$. naufragorum, the only species with noticeable petals when mature, petals continued to expand, reaching the length of stamens (Figure 5M). In the other two species, petal primordia were initiated (Figure $5 \mathrm{~F}-\mathrm{H}$ ) but never expanded, remaining small throughout development (Figure 5J-L) and not visible at maturity (Figure 5N-P).

Histological sections were performed to further investigate the anatomical development of stamens and carpels. Lepidium naufragorum [see Additional file 2] and

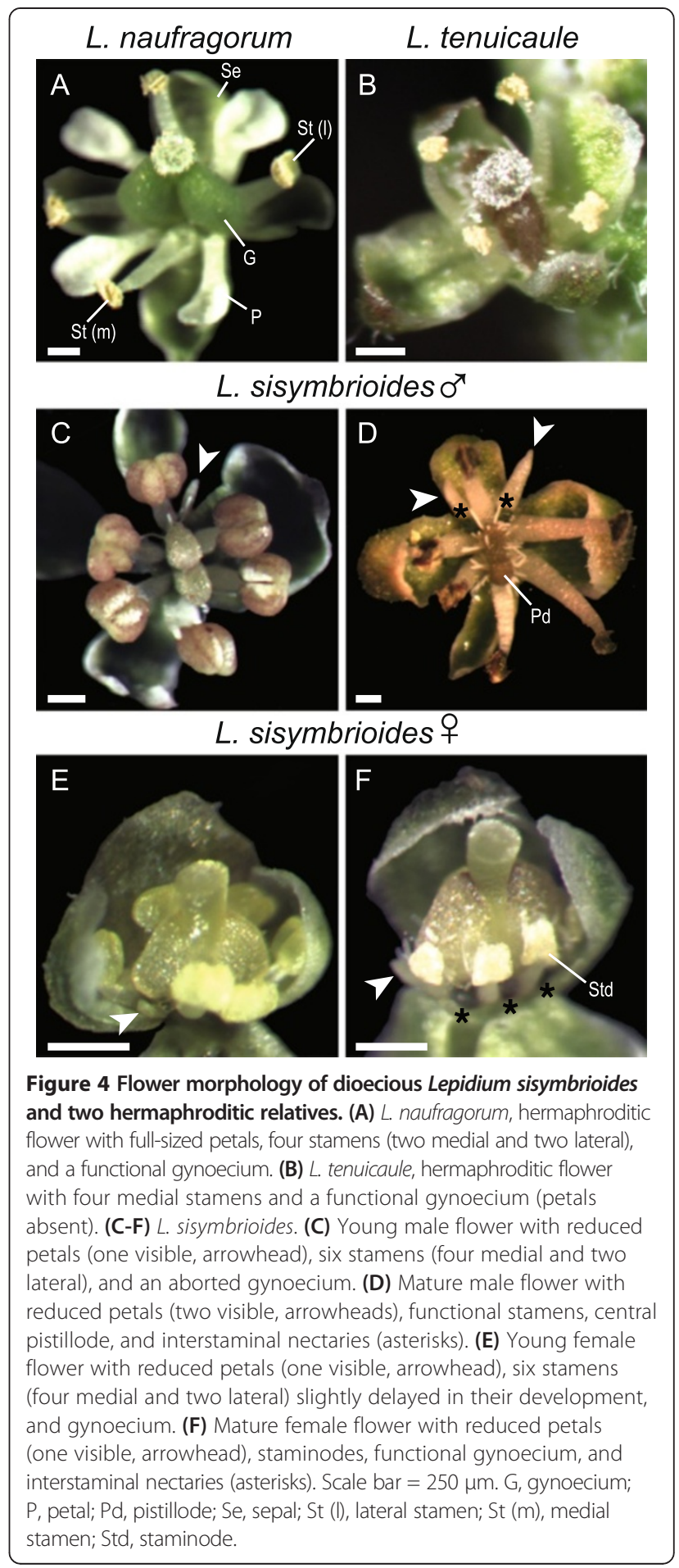

L. tenuicaule revealed comparable reproductive organ development with no evidence of loss of organ function. Therefore, only data from L. tenuicaule is compared here against $L$. sisymbrioides (Figure 6).

In hermaphroditic flowers of $L$. tenuicaule, after stamen filaments and anther locules differentiated (Figure 6A), anthers consisted of PMCs, tapetum and two outer anther 


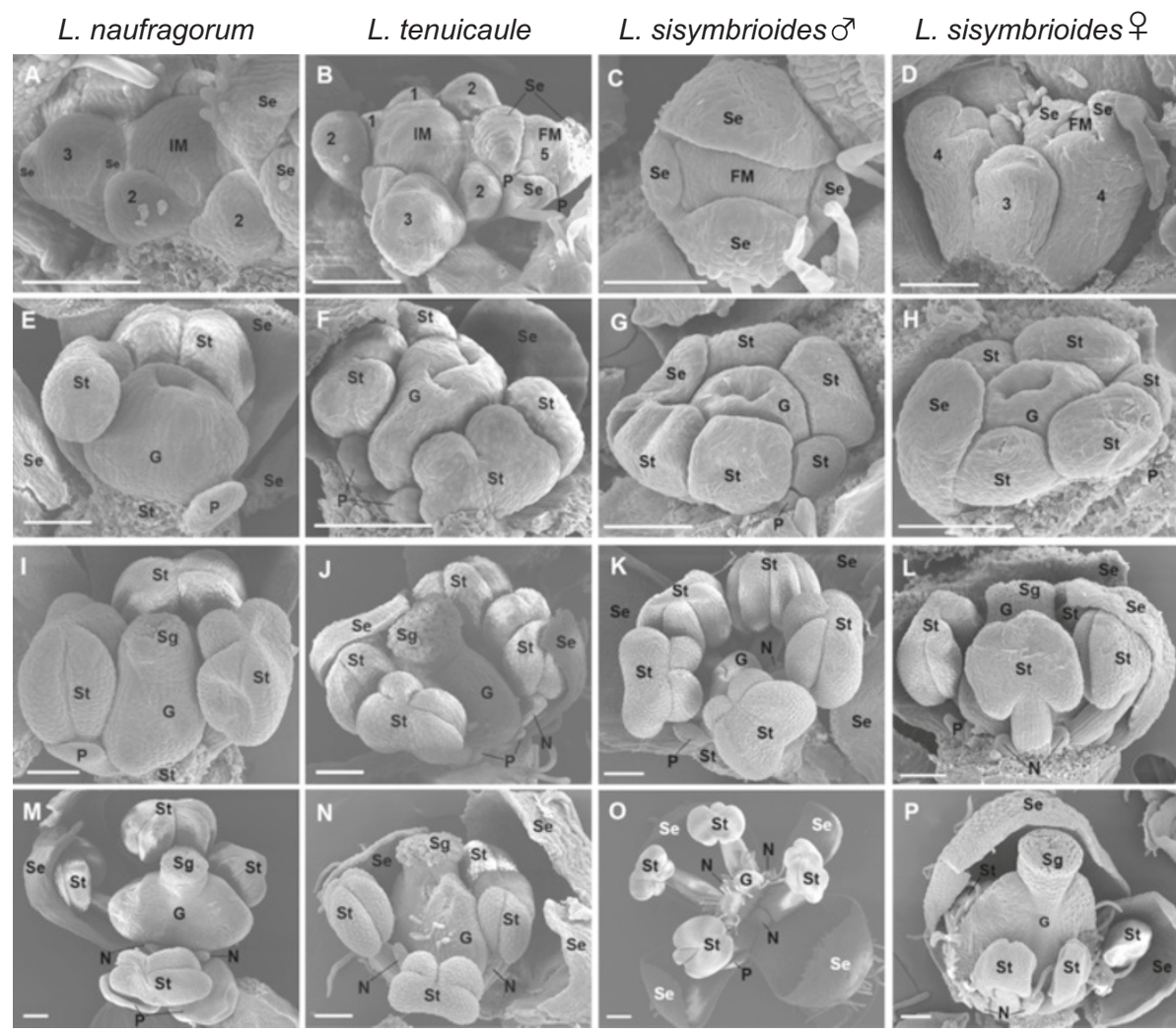

Figure 5 Comparative flower ontogeny of dioecious Lepidium sisymbrioides and two hermaphroditic relatives by scanning electron microscopy. (A, E, I, M) L. naufragorum. (B, F, J, N) L. tenuicaule. (C, G, K, O) Staminate L. sisymbrioides. (D, H, L, P) Carpellate L. sisymbrioides. In some panels, organs have been removed. Floral developmental stages noted below follow Arabidopsis thaliana stages $[20,61,62]$. (A-D) Initiating floral primordia within an inflorescence with sepals beginning to enclose the floral meristem, numbered 1 to 5 according to floral developmental stage. (E-H) Petal, stamen, and gynoecium primordia develop, stages 6 to 8. (I-L) Locules of the androecium have differentiated; gynoecium fuses and begins lateral expansion of carpels and stigmatic papillae begin to develop in $\mathrm{I}-\mathrm{J}$ and $\mathrm{L}$, stages 10 to 11, but arrest in K. (M-P) Stigma differentiates from subtending style in $\mathrm{M}-\mathrm{N}$ and $\mathrm{P}$, stage 12, but arrests in $\mathrm{O}$; stamen filaments expand in $\mathrm{M}-\mathrm{O}$, but remain short in $\mathrm{P}$; petals expand in M, but remain aborted in N-P. Scale bar =100 $\mu \mathrm{m}$ in A-N, P; $200 \mu \mathrm{m}$ in O. FM, floral meristem; G, gynoecium; IM, inflorescence meristem; N, nectary; P, petal; Se, sepal; Sg, stigmatic papillae; St, stamen.

wall layers (middle layer and endothecium; Figure 6D, J, stage 9) and ovules began to develop in gynoecia (Figure 6E, K, stage 9). After meiosis of PMCs, anther wall layers degenerated, microspores underwent mitosis, and integuments enclosed the ovule [see Additional file 2, stage 12]. Subsequently, the androecium and gynoecium matured (Figure 6P). At this stage, the stamen filaments elongated (Figure 6P) and pollen sacs were composed of a single endothecium layer with secondary wall thickenings (Figure 6S, Y, stage 13). Pollen grains could be visualized with evident exine and the tapetum had degraded (Figure 6S, Y, stage 13). By this stage, the gynoecium had fused, elongated, and differentiated a style and stigma (Figure 6P, stage 13), and ovules had differentiated within each carpel (Figure 6T, Z1). Apical ovules consisted of an elongated funiculus and an embryo sac, surrounded by the nucellus and two integuments (Figure 6T, Z1, stage 13).

In staminate flowers of $L$. sisymbrioides, histological sections revealed that after initiation of the gynoecium
(Figure 6B), sporogenous tissue (PMCs) was present in stamen locules (Figure 6F, L) and ovules had been initiated (Figure 6G, M, [see Additional file 2, stage 9]). However at later stages (Figure 6Q, stage 12; [see Additional file 2, stage 11]), as microspores matured within the anthers and the tapetum degenerated (Figure $6 \mathrm{Z2}$ ), the gynoecium failed to elongate and differentiate a style and stigma, and ovules did not grow nor differentiate (Figure $6 \mathrm{U}-\mathrm{V}, \mathrm{Z3}$, [see Additional file 2]). Since the gynoecium arrest occurs before microsporogenesis (the production of tetrads from PMCs, stage 9), which normally precedes megasporogenesis (stage 11) in Arabidopsis, we conclude that the process for the loss of gynoecium function in male flowers is the arrest of development at a pre-meiotic, intermediate stage (stage 9).

In young carpellate flowers of L. sisymbrioides (Figure 6C), sporogenous tissue (PMCs) inside the stamen locules (Figure 6H, N) and ovule initiation (Figure 6I, O) were evident at the same stage as in hermaphroditic flowers 


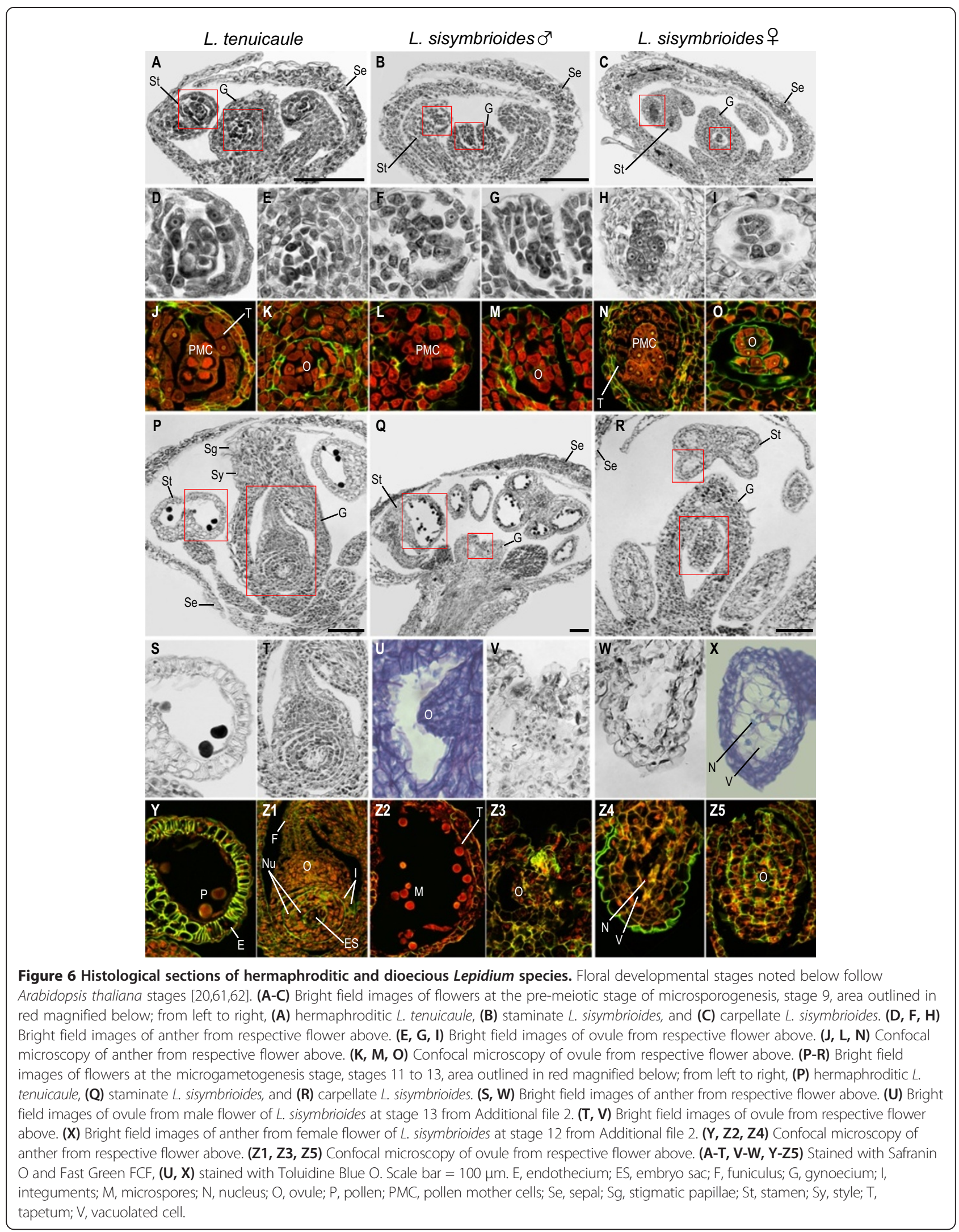


(Figure 6A, D-E, J-K, stage 9). By the time the gynoecium closed and a stigma and ovule began to differentiate (Figure 6R, Z5, [see Additional file 2, stage $11])$, vacuolated cells pervaded anthers and PMCs had degenerated (Figure 6W-X, Z4). Stamen filaments did not elongate and neither tetrads, microspores, nor pollen were produced; pollen sacs appeared shrunken, filled with vacuolated cells, and no endothecium layer developed (Figure 6W-X, Z4). Based on the above observations, we propose that the developmental process for loss of androecium function in female flowers is likely cell death, as evidenced by vacuolated cells (absence of stained cytoplasm) and nuclear degradation (Figure 6W-X, Z4) following the development of PMCs (Figure 6H, N). In conclusion, androecium abortion in female flowers occurs at a comparable pre-meiotic stage to gynoecium abortion in male flowers (stage 9) but due to different processes, that is, cell death versus developmental arrest, respectively. Figure 7 summarizes our SEM and histological observations on flower development in Lepidium study species (Figures 5, 6, [see Additional file 2]) in reference to described developmental stages from $A$. thaliana $[20,61,62]$.

\section{Programmed cell death in anther walls is involved in the degradation of pollen mother cells of female $L$. sisymbrioides flowers}

Because we were finding evidence of cell death in stamens of female L. sisymbrioides, we wanted to determine whether PCD could be responsible for this abortion of stamens. To look for evidence of PCD, as characterized by DNA fragmentation, we conducted TUNEL assays on histological sections of carpellate L. sisymbrioides and, for comparison, staminate L. sisymbrioides and L. tenuicaule flowers. The TUNEL assay attaches fluorescein to fragmented DNA, eliciting a green fluorescent signal in nuclei undergoing DNA degradation. Lepidium tissue autofluoresced in the absence of staining under both DAPI and fluorescein excitation and emission ranges: cell walls, chloroplasts, nuclei, and pollen grains showed background signal (compare Figure $8 \mathrm{~A}-\mathrm{B}$ to $\mathrm{C}-\mathrm{D}, \mathrm{G}-\mathrm{H}$ to I-J, and $\mathrm{M}-\mathrm{N}$ to $\mathrm{O}-\mathrm{P}$ ). This autofluorescence contributed additional histological evidence that cell death was occurring in stamens of female L. sisymbrioides, as evidenced by the absence or degradation of cell walls, nuclei, and pollen in the center of anther locules, where sporogenous tissue leading to pollen normally develops (compare Figure 8I-J to $\mathrm{C}-\mathrm{F}$ and O-R). In spite of this autofluorescence, the use of negative and positive controls allowed us to observe strong, above-background, fluorescein signal in certain tissues at certain stages that indicate DNA degradation. For example, all nuclei in the endothecium of mature, functional anther sacs of $L$. tenuicaule at stage 13 showed a strong, above-background, fluorescein signal indicating PCD (compare Figure 8B to D, red arrow denotes one exemplary nucleus). More importantly, we observed strong, above-background, fluorescein signal in all nuclei throughout all anther wall layers of mature anthers from female L. sisymbrioides (compare Figure $8 \mathrm{H}$ to J, red arrows denote exemplary nuclei from each layer). This was taken as evidence that these nuclei are undergoing DNA degradation, as observed in positive controls (treated with DNase) showing higher than abovebackground signal (compare Figure $8 \mathrm{~B}$ to L, red arrow denotes one exemplary nucleus). When comparing anthers from female L. sisymbrioides that abort at stage 9 to functional anthers from L. tenuicaule and male L. sisymbrioides at the same stage (compare Figure 8I-J to E-F and Q-R), it appeared that PCD in anther wall layers was contributing to the degradation of PMCs in carpellate $L$. sisymbrioides flowers, in which tapetum, endothecium, and tetrads do not develop as in functional anthers from L. tenuicaule and male L. sisymbrioides at the same stage. In summary, using the TUNEL assay as a proxy for PCD, we find evidence for PCD in the anther wall layers of carpellate L. sisymbrioides flowers, which likely contributes to the degradation of PMCs and abortion of anthers at stage 9 .

\section{Discussion}

Lepidium sisymbrioides is the sole dioecious member of Brassicaceae, and our phylogenetic analyses show that it is closely related to three other New Zealand hermaphroditic species: L. kirkii, L. naufragorum and L. tenuicaule (Figures 1, 2). Increased phylogenetic sampling of the PI first intron among AANZ taxa allows us to identify reticulation events leading to $L$. sisymbrioides, which resulted from three past hybridization events (Figure 2). Of the three close relatives, the shared reticulation history with L. kirkii is a novel finding. Molecular, cytological, and genome size analyses provide evidence that L. sisymbrioides is an allo-octoploid (Figures 1, 2 and 3, Table 1), with 64 chromosomes and an average holoploid genome size (1C-value) of $621 \mathrm{Mbp}$. By comparing the floral ontogeny of unisexual flowers in L. sisymbrioides to that of its close relatives and to Arabidopsis thaliana, we show that unisexual flowers in this species arose from selective abortion of reproductive organs at a similar floral developmental stage (Figure 7 stage 9) but by different processes in males and females. Differential abortion of the gynoecium in males appears to result from developmental arrest, while in females anther sterility results from programmed cell death (Figure 6, 8).

\section{Evolution of dioecy and unisexual flowers within Brassicaceae}

The evolution of dioecy in Brassicaceae occurred only once in the genus Lepidium. We infer that in L. sisymbrioides, dioecy evolved from hermaphroditism via selective 


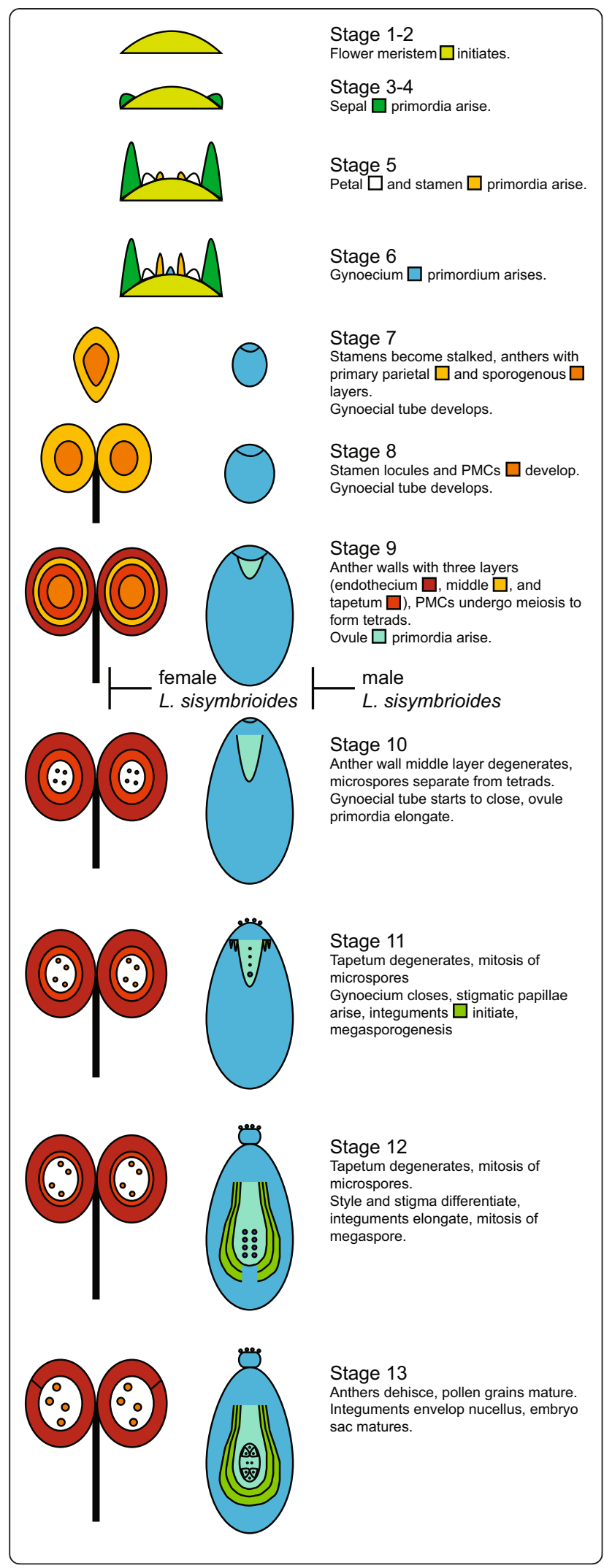

Figure 7 Model for flower development in Lepidium study species, with proposed timing of reproductive organ abortion in dioecious $L$. sisymbrioides. The model is informed by our SEM and histological observations (Figures 5, 6) and follows Arabidopsis thaliana stages, noted on the right $[20,61,62]$. Entire flower shown in stages 1 to 6 , only one stamen (left) and one carpel of the bicarpellate gynoecium (right) shown in stages 7 to 13. A filament differentiates within the stamen in stage 8 , and elongates in stage $9 . \vdash$ stage of abortion for female (left) and male (right) flowers of L. sisymbrioides.

abortion of reproductive organs, as in type I flowers [66], as all other members of Lepidium are hermaphroditic. Our floral ontogeny observations confirmed that reproductive organs are initiated and differentially aborted at the same floral developmental stage in male and female flowers of L. sisymbrioides. The timing of abortion corresponds to Arabidopsis stage 9 (Figures 4, 5, 6 and 7), which is broadly considered an 'intermediate' stage of floral development [22], after primordia initiation but before meiosis. Our ontogeny shows that $L$. sisymbrioides is representative of the majority of angiosperms with type I unisexual flowers that selectively abort reproductive organs at significantly correlated developmental stages between the two sexes [22]. This evidence suggests that similar regulatory switch points underlie male and female developmental pathways as proposed by Diggle et al. [22] and comparable selective forces are at play in the two sexes. However, the developmental stage and process of reproductive organ abortion in unisexual flowers across angiosperms vary widely with different stages and processes occurring at equal frequencies [22].

With regard to the developmental process of organ abortion in L. sisymbrioides, while sporogenous tissue (PMCs) in stamen locules differentiates (Figure 6C, H, N), it quickly degenerates during development of carpellate flowers and becomes vacuolated with degraded nuclei (Figure 6R, W-X, Z4). Programmed cell death, which is involved throughout normal flower development [67], is primarily due to endogenous factors and is evidenced by cell death at a predictable time and location during tissue differentiation [68]. During normal flower development, the tapetum degenerates during microgametogenesis via PCD for proper microspore development and differentiation of pollen, [67]. Other studies have shown that premature tapetal degeneration can lead to male sterility [reviewed in 67]. Therefore, because we observe PCD in anther wall layers before microgametogenesis, this premature tapetal degeneration is likely leading to male sterility in L. sisymbrioides females (Figures 6R, W-X, Z4, 8I-J, [see Additional file 2]).

Two types of PCD occur in plants: autolytic and nonautolytic. The former generally occurs during normal plant development, whereas the latter occurs during plantpathogen interactions [69,70]. Moreover, since loss of cell 


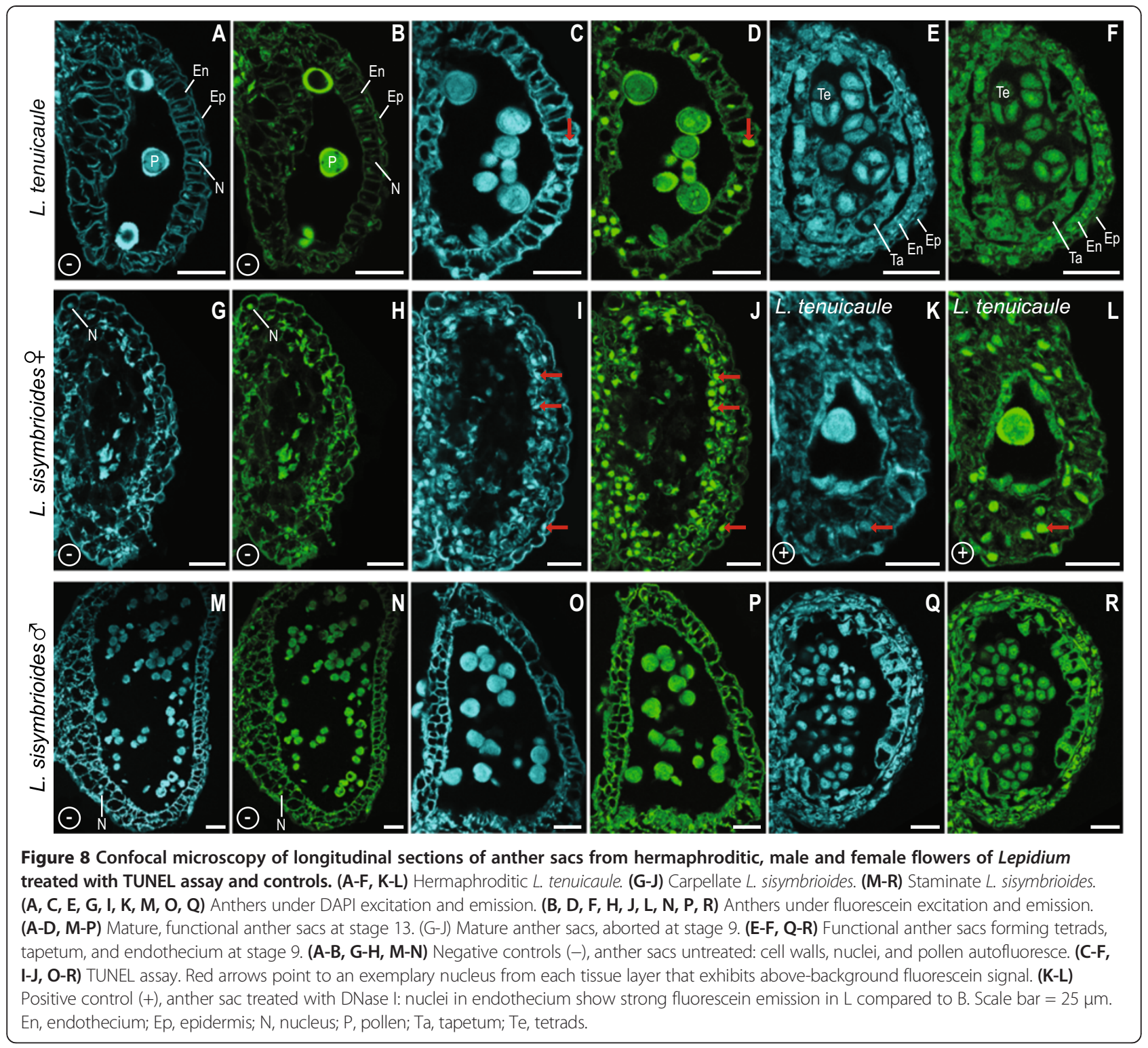

walls and cytoplasm, nuclear condensation, and increase in vacuolar volume are characteristic of autolytic PCD [70], this type of cell death is also likely involved in the degeneration of PMCs in L. sisymbrioides females (Figures 6R, 8I-J, [see Additional file 2]).

In male flowers of L. sisymbrioides, on the other hand, the development of ovules and gynoecia is arrested shortly after initiation of ovule primordia. We found no evidence of cell death, parenchymatization, or change in timing of otherwise normal developmental events in arrested gynoecia. Ovule primordia remain evident in mature male flowers (Figure 6Q, U-V, Z3, Additional file 2). Therefore, of the six developmental processes reviewed in Diggle et al. [22], arrest of development best characterizes the abortion of the gynoecium in L. sisymbrioides males.
Whole genome duplication events via hybridization in the evolution of dioecy in Lepidium

Two different copies of the PI first intron were previously identified among the ANZ taxa (clades A, C); only one copy (clade C) was strongly supported [5]. Our PI phylogeny recovered at least four divergent copies of the first intron in L. sisymbrioides and its close relatives (Figure 1), suggesting ancient allopolyploidization events, followed by divergence of PI alleles. Based on our phylogenetic network analyses, L. sisymbrioides has a history of three allopolyploidization events: hybridization (1) between an Australian and Australian or New Zealand species, (2) with an Asian species, and (3) with an American species (Figure 2). Our study provides new evidence of an additional genome within the 'A' clade of PI [5] and shows an additional PI copy in taxa from this clade (as in, L. kirkii, 
L. naufragorum, L. sisymbrioides and L. tenuicaule; A1A2, Figure 1), which would be expected of four divergent genomes contributing to several allopolyploidization events in our study species. Based on our cytological and genome size estimates, $L$. sisymbrioides is an octoploid, which would require several whole genome duplications. Together with our PI data, this evidence suggests that L. sisymbrioides is an allo-octoploid composed of four different genomes.

Australian Lepidium appear to have undergone a rapid radiation during the Pliocene and Pleistocene, when the arid and cooler regions of the southeastern temperate biomes were expanding [71]. Previous studies suggested at least one dispersal event each from California and South Africa to Australia or New Zealand; most likely colonizing Australia first, with at least two subsequent dispersal events to New Zealand [12]. The majority of Lepidium species produce mucilaginous seeds that adhere to birds [4], which may have facilitated long-distance dispersal among the Americas, Australia, New Zealand and the Old World [72-75]. Our results suggest that a hybridization event occurred either within Australia or between an Australian and a New Zealand ancestor, followed by hybridization with an Asian colonist and an American colonist, resulting in the evolution of $L$. sisymbrioides (Figures 1, 2). Colonization by an Asian ancestor is not well supported by our data and conflicts with previous studies indicating colonization by an African ancestor [12]; this contradictory evidence could be due to the use of different nuclear DNA regions. In spite of this, our results confirm at least two dispersal events to Australia or New Zealand from the New World and Old World that resulted in allopolyploidization, but exact New and Old World ancestry is uncertain. Additionally, we infer a hybridization between ANZ taxa not previously suggested.

Our 1C-value estimates for L. sisymbrioides and L. tenuicaule fall within the reported range for the family ( 0.15 to $2.43 \mathrm{pg}$ [76-78]). Lepidium naufragorum lies outside the high end of the range, consistent with it being highly polyploid (18x [65]). Even though the $1 C$-value of L. sisymbrioides $(0.635 \mathrm{pg})$ is almost fourfold that of Arabidopsis thaliana (0.16 pg [79]), it is comparable to the size of other model plants such as rice (0.5 pg [80]), making it a likely candidate for whole genome sequencing. Genomic resources for this species would facilitate the investigation of sex determination and of the putative chromosomal rearrangements that contributed to the evolution of dioecy after polyploidization. As new technologies and approaches are being developed [81,82], sequencing this octoploid will become more feasible in the near future.

\section{Conclusions}

The developmental process leading to the evolution of dioecy in Lepidium sisymbrioides was placed in the broader context of the historical patterns conditioning the evolution of separate sexes in this unique dioecious relative of Arabidopsis. We have characterized the developmental stage and process of its unisexual flowers, paving the way for future studies aimed at unraveling the genetic basis underlying reproductive organ abortion. Having placed L. sisymbrioides in a phylogenetic context, determined its ploidy, hybridization history, and genome size, and compared it to Arabidopsis thaliana flower development will facilitate the investigation of the role of polyploidy and of potential candidate genes in the evolution of dioecy in Brassicaceae.

\section{Appendix 1}

Voucher information and GenBank accessions for Lepidium taxa (Brassicaceae) sampled in this study. Voucher information provided only for taxa with sequences not downloaded from GenBank. Taxon, collector and collection number, origin, herbarium, PISTILLATA intron.

Lepidium africanum (Burm.f.) DC., AY114216; Lepidium alluaudii Maire, AY114221; Lepidium apetalum Willd., AY114217; Lepidium armoracia Fisch. \& C.A. Mey., AY114218-AY114220; Lepidium aschersonii Thell., AY114222; Lepidium bipinnatifidum Desv., AY114223AY114224; Lepidium bonariense L., AY114225-AY1 14227; Lepidium campestre (L.) R.Br., AY114228; Lepidium chichicara Desv., AY114229-AY114231; Lepidium cordatum Willd. ex Steven, AY114232-AY114233; Lepidium coronopus (L.) Al-Shehbaz, unvouchered, cultivated from wild-collected seed from Madrid, Spain (INIA seed accession 205-0261-68), JN119857; Lepidium davisii Rollins, FJ541471/FJ541473; Lepidium densiflorum Schrad., AY114235-AY114236; Lepidium desvauxii Thell., AY114237; Lepidium dictyotum A. Gray, AY114238; Lepidium flavum Torr., AY114239; Lepidium flexicaule Kirk, AY114240-AY114241; Lepidium fremontii S. Watson, AY114243-AY114244; Lepidium graminifolium L., AY114246; Lepidium heterophyllum Benth., AY114247; Lepidium hirtum (L.) Sm. ssp. calycotrichum (Kunze) Thell., AY114248; Lepidium hyssopifolium Desv., AY114249; Lepidium kirkii Petrie, P. Heenan s.n., cultivated from wild-collected seed from Galloway, New Zealand, CHR, KJ648155-KJ648159; Lepidium lasiocarpum Nutt., AY114250-AY114251; Lepidium latifolium L., AY114252; Lepidium leptopetalum F. Muell., AY114215; Lepidium meyenii Walp., AY114254-AY114255; Lepidium meyeri Claus ssp. meyeri, AY114269; Lepidium monoplocoides F. Muell., AY114256; Lepidium montanum Nutt., AY114257/AY114259; Lepidium myriocarpum Sond., AY114260; Lepidium naufragorum Garn.-Jones \& D.A. Norton, V. Di Stilio 117, cultivated from wild-collected seed from Open Bay Islands, New Zealand, WTU, JN119859-JN119860/JN119862/KJ648160-KJ648165; Lepidium navasii (Pau) Al-Shehbaz, unvouchered, cultivated 
from wild-collected seed from Gádor, Spain (INIA seed accession 204-4472-76), JN119856; Lepidium nitidum Nutt., AY114261-AY114262; Lepidium oblongum Small, AY114263-AY114264; Lepidium oleraceum Sparrm., AY114265; Lepidium oxytrichum Sprague, AY114266AY114267; Lepidium papilliferum (L.F. Hend.) A. Nelson \& J.F. Macbr., FJ541451/FJ541488; Lepidium perfoliatum L., AY114268; Lepidium phlebopetalum (F. Mull.) F. Mull., AY114214; Lepidium pinnatifidum Ledeb., AY114270; Lepidium pseudohyssopifolium Hewson, AY114271-AY114274; Lepidium pseudotasmanicum Thell., AY114275; Lepidium quitense Turcz., AY114276; Lepidium ruderale L., AY114278; Lepidium sativum L., AY114279; Lepidium sisymbrioides Hook. f., V. Soza 1924, cultivated from wild-collected seed from Twizel, South Canterbury, New Zealand, WTU, KJ648166- KJ648169; Lepidium spinosum Ard., AY114280; Lepidium tenuicaule Kirk, V. Di Stilio 116, cultivated from wild-collected seed from Shag Point, New Zealand, WTU, KJ648170- KJ648174; Lepidium vesicarium L., AY114281; Lepidium violaceum (Munby) Al-Shehbaz, unvouchered, cultivated from wild-collected seed from N. Azrou, Morocco (INIA seed accession 2064096-84), JN119858; Lepidium virginicum L., AY114285.

Notes: INIA = Instituto Nacional de Investigaciones Agrarias, Madrid, Spain.

\section{Additional files}

Additional file 1: Staminate flowers of Lepidium sisymbrioides. A) Young staminate flower of $L$. sisymbrioides, showing sepals (Se), five stamens (St), and aborted gynoecium (G). (B) Staminate flower of $L$. sisymbrioides, showing sepals (Se), six nectaries (N) among stamen (St) filaments, and aborted gynoecium (G). Scale bar $=0.25 \mathrm{~mm}$.

Additional file 2: Histological sections of hermaphroditic and dioecious Lepidium species stained with Toluidine Blue 0 . (A-C) Flower at the pre-meiotic stage of microsporogenesis, stage 9; from left to right, (A) hermaphroditic L. naufragorum, (B) staminate L. sisymbrioides, and (C) carpellate L. sisymbrioides. (D, F, H) Anther locule from respective flower above. (E, G, I) Ovule from respective flower above. (J-L) Flowers later on in development, at the microgametogenesis stage, stages 11-12; from left to right, $(J)$ hermaphroditic $L$. naufragorum, $(K)$ staminate $L$. sisymbrioides, and $(L)$ carpellate $L$. sisymbrioides. $(M, O, Q$ ) Anther locule from respective flower above. (N, P, R) Ovule from respective flower above. (S-U) Mature flowers, stage 13; from left to right, (S) hermaphroditic L. naufragorum, (T) staminate L. sisymbrioides, and (U) carpellate $L$. sisymbrioides. $(V, X, Z 1)$ Anther locule from respective flower above. $(W, Y$, Z2) Ovule from respective flower above. Scale bar $=50 \mu \mathrm{m}$ in A-C; $100 \mu \mathrm{m}$ in J-U. E, endothecium; ES, embryo sac; G, gynoecium; I, integuments; M, microspores; N, nucleus; O, ovule; $\mathrm{P}$, pollen; PMC, pollen mother cells; $\mathrm{Se}$, sepals; Sg, stigmatic papillae; St, stamen; Sy = style; T, tapetum; V = vacuolated cell.

\section{Abbreviations}

AANZ: American, Australian, and New Zealand; ANZ: Australian and New Zealand; bs: bootstrap; BSA: bovine serum albumin; CEN: chicken erythrocyte nuclei; DAPI: 4',6-diamidino-2-phenylindole; FAA: formaldehyde-acetic acid-alcohol; Mbp: millions of base pairs; PBS: phosphate buffered solution; PCD: programmed cell death; pg: picogram; Pl: PISTILLATA; PMCs: pollen mother cells; pp: posterior probabilities; SEM: scanning electron microscopy.
Competing interests

The authors declare that they have no competing interests.

\section{Authors' contributions}

VLH conducted SEM observations of flower development and contributed to figures. VLS conducted DNA extractions, PCR, cloning, and sequencing, prepared PI alignments, conducted phylogenetic and network analyses, performed cytological and histological observations, and drafted the manuscript. VSD conceived, designed, and coordinated the study, collected genome size data, and participated in drafting and editing the manuscript. All authors read and approved the final manuscript.

\section{Acknowledgements}

The authors thank Peter Heenan for field collection of seeds from $L$. naufragorum, L. sisymbrioides, and L. tenuicaule; John Bowman for PI alignments; CHR for the herbarium specimen of L. kirkii; Luca Comai and Jerry Davison for training and assistance with flow cytometry; Parisa AalamiMonelli, Nadya Ali, Wai Pang Chan, Caitlin Connelly, Brittany Ng, and Patricia Salles Smith for assistance with data collection; Doug Ewing and Nora Kozlov for seed germination and plant care; Starr Matsushita and Delene Oldenberg for assistance with cytology; Cindy Skema for histological advice; University of Washington, Department of Biology funds to VSD; and anonymous reviewers for helpful suggestions.

Received: 21 June 2014 Accepted: 7 October 2014

Published: 12 November 2014

\section{References}

1. Al-Shehbaz IA, Beilstein MA, Kellogg EA: Systematics and phylogeny of the Brassicaceae (Cruciferae): an overview. Plant Syst Evol 2006, 259:89-120.

2. Warwick SI, Al-Shehbaz IA: Brassicaceae: chromosome number index and database on CD-Rom. Plant Syst Evol 2006, 259:237-248.

3. Endress PK: Evolution and floral diversity: the phylogenetic surroundings of Arabidopsis and Antirrhinum. Int J Plant Sci 1992, 153:S106-S122.

4. Al-Shehbaz IA: The genera of Lepidieae (Cruciferae, Brassicaceae) in the Southeastern United States. J Arnold Arboretum 1986, 67:265-311.

5. Lee JY, Mummenhoff $\mathrm{K}$, Bowman JL: Allopolyploidization and evolution of species with reduced floral structures in Lepidium L. (Brassicaceae). Proc Natl Acad Sci 2002, 99:16835-16840.

6. Kirk T: The Students' Flora of New Zealand and the Outlying Islands. Wellington, New Zealand: John Mackay, Government Printer; 1899

7. Bateman AJ: Note on dioecy in the Cruciferae. Heredity 1955, 9:415-415.

8. Webb CJ, Sykes WR, Garnock-Jones PJ: Flora of New Zealand: Naturalised Pteridophytes, Gymnosperms, Dicotyledons, Volume IV. Botany Division D. S. I. R.: Christchurch, New Zealand; 1988.

9. Mummenhoff K, Brueggemann H, Bowman JL: Chloroplast DNA phylogeny and biogeography of Lepidium (Brassicaceae). Am J Bot 2001, 88:2051-2063.

10. Heenan PB, Mitchell AD, McLenachan PA, Lockhart PJ, de Lange PJ: Natural variation and conservation of Lepidium sisymbrioides Hook, $f$. and $L$. solandri Kirk (Brassicaceae) in South Island, New Zealand, based on morphological and DNA sequence data. N Z J Bot 2007, 45:237-264.

11. Allan HH: Flora of New Zealand. Volume I. Indigenous Tracheophyta (Psilopsida, Lycopsida, Filicopsida, Gymnospermae, Dicotyledones). R. E. Owen, Government Printer: Wellington, New Zealand; 1961.

12. Mummenhoff $K$, Linder $P$, Friesen N, Bowman JL, Lee J-Y, Franzke A: Molecular evidence for bicontinental hybridogenous genomic constitution in Lepidium sensu stricto (Brassicaceae) species from Australia and New Zealand. Am J Bot 2004, 91:254-261.

13. Miller JS, Venable DL: Polyploidy and the evolution of gender dimorphism in plants. Science 2000, 289:2335-2338.

14. Miller JS, Venable DL: The transition to gender dimorphism on an evolutionary background of self-incompatibilty: an example from Lycium (Solanaceae). Am J Bot 2002, 89:1907-1915.

15. Spigler RB, Lewers KS, Johnson AL, Ashman TL: Comparative mapping reveals autosomal origin of sex chromosome in octoploid Fragaria virginiana. J Hered 2010, 101:S107-S117.

16. Sakai AK, Weller SG: Gender and sexual dimorphism in flowering plants: a review of terminology, biogeographic patterns, ecological correlates, and phylogenetic approaches. In Gender and Sexual Dimorphism in Flowering Plants. Berlin, Germany: Springer; 1999:1-32.

17. Godley EJ: Flower biology in New Zealand. N Z J Bot 1979, 17:441-466. 
18. Jesson LK: Ecological correlates of diversification in New Zealand angiosperm lineages. N Z J Bot 2007, 45:35-51.

19. Beilstein MA, Nagalingum NS, Clements MD, Manchester SR, Mathews S: Dated molecular phylogenies indicate a Miocene origin for Arabidopsis thaliana. Proc Natl Acad Sci 2010, 107:18724-18728.

20. Bowman JL: Arabidopsis: An Atlas of Morphology and Development. New York: Springer; 1994.

21. $\mathrm{Ma} \mathrm{H}$ : Molecular genetic analyses of microsporogenesis and microgametogenesis in flowering plants. Annu Rev Plant Biol 2005, 56:393-434.

22. Diggle PK, Di Stilio VS, Gschwend AR, Golenberg EM, Moore RC, Russell JRW, Sinclair JP: Multiple developmental processes underlie sex differentiation in angiosperms. Trends Genet 2011, 27:368-376.

23. De Lange PJ, Norton DA, Courtney SP, Heenan PB, Barkla JW, Cameron EK, Hitchmough R, Townsend AJ: Threatened and uncommon plants of New Zealand (2008 revision). N Z J Bot 2009, 47:61-96.

24. Mitchell AD, Heenan PB: Systematic relationships of New Zealand endemic Brassicaceae inferred from nrDNA ITS sequence data. Syst Bot 2000, 25:98.

25. Mummenhoff K, Polster A, Muehlhausen A, Theissen G: Lepidium as a model system for studying the evolution of fruit development in Brassicaceae. J Exp Bot 2009, 60:1503-1513.

26. Hughey JR, Silva PC, Hommersand MH: Solving taxonomic and nomenclatural problems in Pacific Gigartinaceae (Rhodophyta) using DNA from type material. J Phycol 2001, 37:1091-1109.

27. Maddison DR, Maddison WP: MacClade 4: Analysis of Phylogeny and Character Evolution. Sunderland, MA: Sinauer Associates; 2005.

28. Martin DP, Lemey P, Lott M, Moulton V, Posada D, Lefeuvre P: RDP3: a flexible and fast computer program for analyzing recombination. Bioinformatics 2010, 26:2462-2463.

29. Martin D, Rybicki E: RDP: detection of recombination amongst aligned sequences. Bioinformatics 2000, 16:562-563.

30. Martin DP, Posada D, Crandall KA, Williamson C: A modified bootscan algorithm for automated identification of recombinant sequences and recombination breakpoints. AIDS Res Hum Retroviruses 2005, 21:98-102.

31. Padidam M, Sawyer S, Fauquet CM: Possible emergence of new geminiviruses by frequent recombination. Virology 1999, 265:218-225.

32. Smith JM: Analyzing the mosaic structure of genes. J Mol Evol 1992, 34:126-129.

33. Posada D, Crandall KA: Evaluation of methods for detecting recombination from DNA sequences: computer simulations. Proc Nat/ Acad Sci U S A 2001, 98:13757-13762.

34. Gibbs MJ, Armstrong JS, Gibbs AJ: Sister-Scanning: a Monte Carlo procedure for assessing signals in recombinant sequences. Bioinformatics 2000, 16:573-582.

35. Boni MF, Posada D, Feldman MW: An exact nonparametric method for inferring mosaic structure in sequence triplets. Genetics 2007, 176:1035-1047.

36. Holmes EC, Worobey M, Rambaut A: Phylogenetic evidence for recombination in dengue virus. Mol Biol Evol 1999, 16:405-409.

37. Guindon S, Gascuel O: A simple, fast, and accurate algorithm to estimate large phylogenies by maximum likelihood. Syst Biol 2003, 52:696-704.

38. Darriba D, Taboada GL, Doallo R, Posada D: jModelTest 2: more models, new heuristics and parallel computing. Nat Methods 2012, 9:772-772.

39. Akaike $\mathrm{H}$ : A new look at the statistical model identification. IEEE Trans Autom Control 1974, AC19:716-723.

40. Smith JF, Stillman AJ, Larson SR, Culumber CM, Robertson IC, Novak SJ: Phylogenetic relationships among Lepidium papilliferum (L. Henderson) A. Nels. \& J. F. Macbr., L. montanum Nutt., and L. davisii Rollins (Brassicaceae). J Torrey Botanical Society 2009, 136:149-163.

41. Huelsenbeck JP, Ronquist F: MRBAYES: Bayesian inference of phylogenetic trees. Bioinformatics 2001, 17:754-755

42. Ronquist F, Huelsenbeck JP: MrBayes 3: Bayesian phylogenetic inference under mixed models. Bioinformatics 2003, 19:1572-1574

43. Miller MA, Pfeiffer W, Schwartz T: Creating the CIPRES Science Gateway for inference of large phylogenetic trees. In Proceedings of the Gateway Computing Environments Workshop (GCE), 2010. New Orleans, LA: Institute of Electrical and Electronics Engineers; 2010:1-8.

44. Yang ZH, Rannala B: Bayesian phylogenetic inference using DNA sequences: a Markov Chain Monte Carlo method. Mol Biol Evol 1997 14:717-724

45. Rambaut A: FigTree Version 1.4. 2012. [http://tree.bio.ed.ac.uk/software/figtree/]
46. Zwickl DJ: Genetic algorithm approaches for the phylogenetic analysis of large biological sequence datasets under the maximum likelihood criterion. Austin: The University of Texas; 2006

47. Felsenstein J: Confidence limits on phylogenies: an approach using the bootstrap. Evolution 1985, 39:783-791

48. Sukumaran J, Holder MT: DendroPy: a Python library for phylogenetic computing. Bioinformatics 2010, 26:1569-1571.

49. Huson DH, Scornavacca C: Dendroscope 3: an interactive tool for rooted phylogenetic trees and networks. Syst Biol 2012, 61:1061-1067.

50. Huber KT, Oxelman B, Lott M, Moulton V: Reconstructing the evolutionary history of polyploids from multilabeled trees. Mol Biol Evol 2006, 23:1784-1791.

51. Kato A: Air drying method using nitrous oxide for chromosome counting in maize. Biotech Histochem 1999, 74:160-166.

52. Matsushita SC, Tyagi AP, Thornton GM, Pires JC, Madlung A: Allopolyploidization lays the foundation for evolution of distinct populations: evidence from analysis of synthetic Arabidopsis allohexaploids. Genetics 2012, 191:535-547

53. Wright KM, Pires JC, Madlung A: Mitotic instability in resynthesized and natural polyploids of the genus Arabidopsis (Brassicaceae). Am J Bot 2009, 96:1656-1664

54. Greilhuber J, Dolezel J, Lysak MA, Bennett MD: The origin, evolution and proposed stabilization of the terms "genome size" and "C-value" to describe nuclear DNA contents. Ann Bot 2005, 95:255-260.

55. Davison J, Tyagi A, Comai L: Large-scale polymorphism of heterochromatic repeats in the DNA of Arabidopsis thaliana. BMC Plant Biol 2007, 7:44

56. Gregory TR: Animal Genome Size Database. 2013 [www.genomesize.com]

57. Dolezel J, Greilhuber J: Nuclear genome size: are we getting closer? Cytometry A 2010, 77:635-642.

58. Dolezel J, Bartos J, Voglmayr H, Greilhuber J: Nuclear DNA content and genome size of trout and human. Cytometry A 2003, 51A:127-128.

59. Bowman JL, Smyth DR: Patterns of petal and stamen reduction in Australian species of Lepidium L. (Brassicaceae). Int J Plant Sci 1998, 159:65-74.

60. Chehregani A, Sedaghat M: Pollen grain and ovule development in Lepidium vesicarium (Brassicaceae). Int J Agriculture \& Biology 2009, 11:601-605.

61. Muller A: Zur Charakterisierung der Bluten und Infloreszenzen von Arabidopsis thaliana (L.) Heynh. Kulturpflanze 1961, 9:364-393.

62. Smyth DR, Bowman JL, Meyerowitz EM: Early flower development in Arabidopsis. Plant Cell 1990, 2:755-767.

63. Kramer EM: Methods for studying the evolution of plant reproductive structures: comparative gene expression techniques. In Molecular Evolution: Producing the Biochemical Data, Part B. Volume 395. Edited by Zimmer EA, Roalson EH. San Diego, CA: Elsevier Academic Press; 2005:617-636.

64. Johansen DA: Plant Microtechnique. New York. London: McGraw-Hill Book Company, Inc.; 1940

65. De Lange PJ, Murray BG: Contributions to a chromosome atlas of the New Zealand flora - 37. Miscellaneous families. N Z J Bot 2002, 40:1-23.

66. Mitchell $\mathrm{CH}$, Diggle PK: The evolution of unisexual flowers: morphological and functional convergence results from diverse developmental transitions. Am J Bot 2005, 92:1068-1076.

67. Wu HM, Cheung AY: Programmed cell death in plant reproduction. Plant MolBiol 2000, 44:267-281.

68. Noodén LD: Plant Cell Death Processes. San Diego, CA: Elsevier Academic Press; 2004.

69. Van Doorn WG, Beers EP, Dangl JL, Franklin-Tong VE, Gallois P, Hara-Nishimura I, Jones AM, Kawai-Yamada M, Lam E, Mundy J: Morphological classification of plant cell deaths. Cell Death \& Differentiation 2011, 18:1241-1246.

70. Van Doorn WG: Classes of programmed cell death in plants, compared to those in animals. J Exp Bot 2011, 62:4749-4761.

71. Crisp M, Cook L, Steane D: Radiation of the Australian flora: what can comparisons of molecular phylogenies across multiple taxa tell us about the evolution of diversity in present-day communities? Philos Trans $R$ SoC Lond B Biol Sci 2004, 359:1551-1571.

72. Carlquist S: The biota of long-distance dispersal. V. Plant dispersal to Pacific Islands. Bulletin of the Torrey Botanical Club 1967, 94:129-162.

73. Niemi A: Lepidium ruderale L. on gull skerries in the archipelago SW of Helsingfors. Memoranda Societatis pro Fauna et Flora Fennica 1968, 44:5-12. 
74. Mummenhoff $\mathrm{K}$, Hurka $\mathrm{H}$, Bandelt $\mathrm{H}$ : Systematics of Australian Lepidium species (Brassicaceae) and implications for their origin - evidence from IEF analysis of RUBISCO. Plant Syst Evol 1992, 183:99-112.

75. Garnock-Jones P, Norton D: Lepidium naufragorum (Brassicaceae), a new species from Westland, and notes on other New Zealand coastal species of Lepidium. N Z J Bot 1995, 33:43-51.

76. Johnston JS, Pepper AE, Hall AE, Chen ZJ, Hodnett G, Drabek J, Lopez R, Price HJ: Evolution of genome size in Brassicaceae. Ann Bot 2005, 95:229-235.

77. Oyama RK, Clauss MJ, Formanová N, Kroymann J, Schmid KJ, Vogel H, Weniger K, Windsor AJ, Mitchell-Olds T: The shrunken genome of Arabidopsis thaliana. Plant Syst Evol 2008, 273:257-271.

78. Lysak MA, Koch MA, Beaulieu JM, Meister A, Leitch IJ: The dynamic ups and downs of genome size evolution in Brassicaceae. Mol Biol Evol 2009, 26:85-98.

79. Bennett MD, Leitch IJ, Price HJ, Johnston JS: Comparisons with Caenorhabditis (similar to $100 \mathrm{Mb}$ ) and Drosophila (similar to $175 \mathrm{Mb}$ ) using flow cytometry show genome size in Arabidopsis to be similar to $157 \mathrm{Mb}$ and thus similar to $25 \%$ larger than the Arabidopsis genome initiative estimate of similar to $125 \mathrm{Mb}$. Ann Bot 2003, 91:547-557.

80. Bennett MD, Smith JB: Nuclear DNA amounts in angiosperms. Philos Trans R Soc Lond B Biol Sci 1991, 334:309-345.

81. Burton JN, Adey A, Patwardhan RP, Qiu R, Kitzman JO, Shendure J: Chromosome-scale scaffolding of de novo genome assemblies based on chromatin interactions. Nat Biotechnol 2013, 31:1119-1125.

82. Krasileva K, Buffalo V, Bailey P, Pearce S, Ayling S, Tabbita F, Soria M, Wang S, Consortium I, Akhunov E, Uauy C, Dubcovsky J: Separating homeologs by phasing in the tetraploid wheat transcriptome. Genome Biol 2013, 14:R66.

doi:10.1186/2041-9139-5-42

Cite this article as: Soza et al:: Pattern and process in the evolution of the sole dioecious member of Brassicaceae. EvoDevo 2014 5:42.

\section{Submit your next manuscript to BioMed Central and take full advantage of:}

- Convenient online submission

- Thorough peer review

- No space constraints or color figure charges

- Immediate publication on acceptance

- Inclusion in PubMed, CAS, Scopus and Google Scholar

- Research which is freely available for redistribution 